\title{
Application of TOPSIS Method Based on Utility Theory in Financial Performance Evaluation of Listed Companies
}

\author{
Ge Hong*
}

School of Business Administration, Nanchang Institute of Technology, Nanchang City, Jiangxi Province, 330099, China

\begin{abstract}
Financial evaluation of listed companies is realized by taking debt paying ability, profitability and operation ability as evaluation standards with the aim of investigating financial situations of companies comprehensively and systematically. The paper puts forward an improved TOPSIS decision-making method. In this method, opinions of more subjective policy makers have been involved: decision makers' evaluation of property utility rather than original data is applied; policy makers' effect is reflected by fuzzy numbers in order to know values of fuzzy uncertainty. In the meantime, in view of inaccurate definition of utility values of property data by decision makers, fuzzy numbers are used to describe utility values of property data. Decision makers' consideration about comprehensiveness and balance of property utility of optimal decision-making schemes is involved, while Ward analysis is further conducted to financial performances. At last, rationality and effectiveness of the method are verified through analysis of specific instances about financial performance evaluation.
\end{abstract}

Keywords: Financial performances, TOPSIS decision-making method, utility theory.

\section{INTRODUCTION}

Financial evaluation determined by an investor lays a foundation for investment values of a listed company as well as a foundation for management of a production company to make decisions regarding business and finance. Market supervision organizations determine financial conditions of the company and take supervision measures to satisfy them. Hence, establishment of a scientific investment mode for financial evaluation of listed companies is important for company governance and market supervision.

Since Taylor's establishment of a scientific management theory, company financial evaluation has always been a hot topic in economic management field. Alexander Wall (1928) [1] - pioneer of comprehensive financial evaluation combined 7 financial ratios by linear relations in order to evaluate financial credit level of enterprises. Based on Wall scoring method, scholars also put forward a comprehensive scoring method and distributed 3 aspects including profitability, debt paying ability and growth ability of financial conditions as per the ratio of 5:3:2 [2]. After 1980s, foreign researches on company financial evaluation developed continuously and deeply along with gradually enriched and perfected financial evaluation indexes and comprehensive evaluation methods. Coicoechea A (1992) [3], Salminen P (1998) [4], Bell Michelle L and Benjamin F (2003) [5] et al. conducted tentative researches on selection of multiple-index evaluation methods.

The paper puts forward an improved TOPSIS decisionmaking method, which has integrated more subjective intentions of decision makers. Rationality and effectiveness of the method are verified by analyzing a specific instance of financial performance evaluation.

\section{TOPSIS DECISION-MAKING METHOD BASED ON UTILITY THEORY}

\subsection{Generation of Each Property Utility Function}

Decision-making behaviors of general rational decision makers are not ideal risk-type decisions, conservation-type decisions or neutral-type decisions, while a typical decisionmaking behavior is dominant in a certain interval. Hence, without loss of generality, the utility curve to specify the benefit-type property is an S-shaped curve,

$U(\mathrm{a})=\frac{1}{1+e^{-a}}$

As shown in Fig. (1), when the property value $a<-1$, the decision maker responds relatively obtusely to benefit losses, and is relatively sensitive to benefit increase on the contrary. At this time, the decision maker is a risk-type decision maker; when $a$ stays within the interval of [-1,1], the decision maker thinks that benefit increase nearly has an equal ratio relation with increase in utility value and the decision maker is a neutral-type decision maker at this moment; when $a>1$, the decision maker is relatively sensitive to benefit losses and responses relatively obtusely to benefit increase, namely that the decision maker is a conservation-type decision maker.

Similar to the utility curve of the benefit-type property, the utility curve of the cost-type property is reverse-Sshaped.

$U(\mathrm{a})=\frac{1}{1+e^{a}}$ 


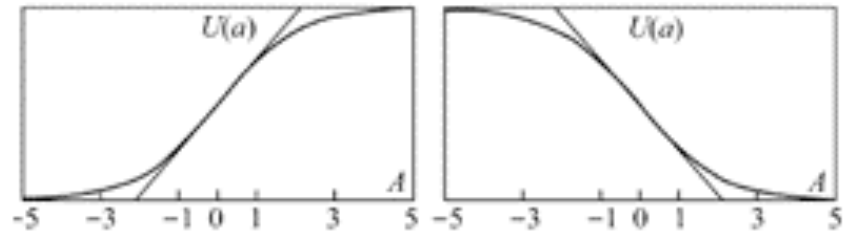

(a) Benefit-type Property (b) Cost-type Property

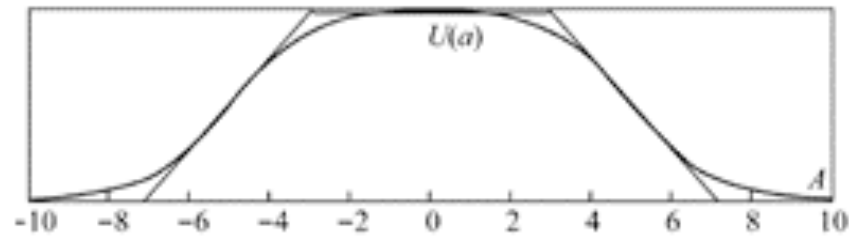

(c) Interval-type Property Index

Fig. (1). Property utility curve.

Aiming at the benefit-type property or cost-type property, the interval $\left[b_{1}, b_{2}\right]$ for the property utility linear changes as speculated by the decision maker is firstly determined by asking. Standardization handling is then carried out by the following formula and utility values are obtained by formula (1) or (2).

$a(b)=\frac{2 b-b_{1}-b_{2}}{b_{2}-b_{1}}$

The utility curve of interval-type property indexes is single-saddle-shaped, namely that when $a$ stays in the interval of $\left[a_{1}, a_{2}\right]$, the property utility value is kept at a constant 1 ; when $a<a_{1}$, the benefit-type property utility is featured by the utility curve; when $a>a_{2}$, the utility curve is featured by cost-type property utility. As for the utility curve of an interval-type property index, the interval $\left[a_{1}, a_{2}\right]$ as well as intervals $\left[b_{1}, b_{2}\right]$ and $\left[b_{3}, b_{4}\right]$ for linear changes of property utility values can be determined by asking. Standardization handling is then carried out by the following formula:

$$
a(b)= \begin{cases}0 & b \in\left[a_{1}, a_{2}\right] \\ \frac{2 b-b_{1}-b_{2}}{b_{2}-b_{1}} & b<a_{1}, b_{2}<b_{3} \\ \frac{2 b-b_{3}-b_{4}}{b_{4}-b_{3}} & b>a_{2}\end{cases}
$$

At last, utility of the property value is worked out.

$$
U(a)= \begin{cases}\frac{1}{1+e^{-a-t}} & a<0 \\ 1 & a>0\end{cases}
$$

where: $t$ is an accuracy parameter. For example, the interval property utility function curve when $t=5$ is shown in Fig. (1).
In addition, in view of uncertainty and fuzziness in utility function determination, the utility values in utility functions determined in the paper are expressed by fuzzy numbers.

\subsection{Setting of Property Weight}

The weight coefficient of each property is set in the form of a judgment matrix in the analytic hierarchy process, namely a ratio of $1 \sim 9$ is used to scale relative importance among properties. Meanwhile, before calculation of each property weight through the judgment matrix, a consistency check shall be carried out to the judgment matrix, namely that the random consistency ratio parameter of the judgment matrix is calculated. Only when $\mathrm{CR}<0.1$, the weight coefficient worked out by the judgment matrix can be affirmed to have satisfying rationality. Otherwise, the decision maker shall readjust the judgment matrix to let it have satisfying consistency.

\subsection{Calculation of Each Property Utility Value}

A utility function and a utility curve are used to determine a utility value of a specific property value. In the meantime, the utility curve of each kind of property data determined by asking the decision maker is inaccurate to a certain extent, so the paper uses fuzzy numbers to express calculated utility values $[6,7]$. It is hereby defined that the utility value calculated with a utility function is a triangular fuzzy number, namely $A=(\mathrm{a}, \mathrm{m}, \mathrm{n})$. As shown in Fig. (2), the membership function of a triangular fuzzy number is:

$\mu_{A}(x)=\left\{\begin{array}{lr}0 & x<m \\ \frac{x-m}{a-m} & m \leq x \leq n \\ \frac{x-n}{a-n} & a \leq x \leq a \\ 0 & x>n\end{array}\right.$

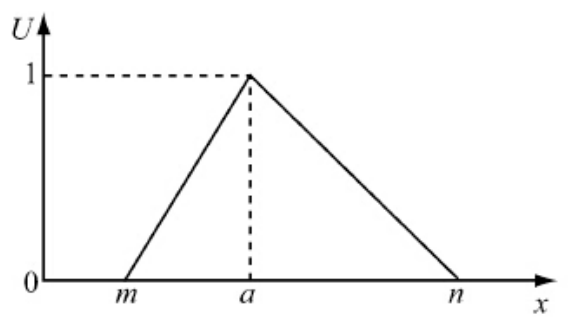

Fig. (2). Membership function of triangular fuzzy number.

The distance between two triangular fuzzy numbers $A=(\mathrm{a}, \mathrm{m}, \mathrm{n})$ and $B=(\mathrm{b}, \mathrm{s}, \mathrm{t})$ can be calculated as per the following formula:

$d(A, B)=\sqrt{\frac{(a-b)^{2}+(a-m-b+s)^{2}+(a+n-b-t)^{2}}{3}}$

\subsection{Determination of Positive Ideal Solution and Nega- tive Ideal Solution}

Utility mapping is carried out to property data before. Hence, the positive ideal solution of each property index is a 
triangular fuzzy number with the highest utility value. In view of the value range $[0,1]$ of a utility function, a positive ideal solution is defined as a triangular fuzzy number $(1,0,0)$ while a negative ideal solution is defined as a triangular fuzzy number $(0,0,0)$. Hence, the formula to work out distances from each property utility fuzzy number to its ideal solutions is as follows:

$$
\left.\begin{array}{l}
d\left(A, Z^{+}\right)=\sqrt{\frac{(a-1)^{2}+(a-m-1)^{2}+(a+n-1)^{2}}{3}} \\
d\left(A, Z^{-}\right)=\sqrt{\frac{a^{2}+(a-m)^{2}+(a+n)^{2}}{3}}
\end{array}\right\}
$$

\subsection{Similarity Degree Calculation}

It is assumed that each property weight vector is $W=\left[\omega_{1}, \omega_{2}, \omega_{\mathrm{n}}\right]$ while weighting Euclidean distances between each alternative scheme and positive and negative ideal solutions are as follows:

$$
\left.\begin{array}{l}
\mathrm{D}\left(A_{j},+\right)=\sqrt{\sum_{i=1}^{n} \omega_{i}\left[d\left(U_{i}\left(a_{j}, i\right),+\right]^{2}\right.} \\
\mathrm{D}\left(A_{j},-\right)=\sqrt{\sum_{i=1}^{n} \omega_{i}\left[d\left(U_{i}\left(a_{j}, i\right),-\right]^{2}\right.}
\end{array}\right\}
$$

where: $U_{i}\left(\mathrm{a}_{\mathrm{j}}, \mathrm{i}\right)$ is the triangular fuzzy number value of a utility function corresponding to the $i$ property value of the $j$ alternative scheme; $d\left(U_{i}\left(a_{j}, i\right),+\right)$ refers to the distance between the property utility value and a positive ideal solution; $d\left(U_{i}\left(a_{j}, i\right),-\right)$ refers to the distance between the property utility value and a negative ideal solution.

The relative similarity degree $c_{j}$ between a scheme and ideal solutions can be worked out by $D\left(A_{j},+\right)$ and $D\left(A_{j},-\right)$, namely:

$c_{j}=\frac{D\left(A_{j},-\right)}{\left[D\left(\mathrm{~A}_{\mathrm{j}},-\right)+\mathrm{D}\left(\mathrm{A}_{\mathrm{j}},+\right)\right]}$

$c_{j}$ can reflect advantages and disadvantages of each alternative scheme from an aspect, but neglects the balance degree of each property utility $[8,9]$. Hence, the paper introduces a variation index to reflect the dispersion degree of each property of an alternative scheme and selects the standard deviation form to work out a variation coefficient of the alternative scheme.

It is assumed that $d(j,+)$ and $d(j,-)$ are mean values of distances between each property utility value of the alternative scheme $j$ and positive and negative ideal solutions, namely:

$$
d(j,+)=\sum_{i=1}^{n} d\left(U_{i}\left(a_{j}, i\right),+\right) d(j,-)=\sum_{i=1}^{n} d\left(U_{i}\left(a_{j}, i\right),-\right)
$$

Standard deviation of each property utility value is:

$$
\begin{aligned}
& S_{j}^{+}=\sqrt{\left.\frac{1}{n-1} \sum_{i=1}^{n} d\left(U_{i}\left(a_{j}, i\right),+\right)-d(j,+)\right)^{2}} \\
& S_{j}^{-}=\sqrt{\left.\frac{1}{n-1} \sum_{i=1}^{n} d\left(U_{i}\left(a_{j}, i\right),-\right)-d(j,-)\right)^{2}}
\end{aligned}
$$

So the calculation formula of variation coefficient of the property utility value of the alternative scheme is:

$$
\theta=\frac{\left[S_{j}^{+}+S_{j}^{-}\right]}{[d(j,+)+d(j,-)]}
$$

The calculation formula of the evaluation value of the final alternative scheme is:

$$
D\left(A_{j}\right)=\left(1-\theta_{j}\right) c_{j}
$$

\section{WARD CLUSTER ANALYSIS OF FINANCIAL PERFORMANCES}

Ward cluster analysis is used to reveal significant differences among financial performances of different listed companies. Ward cluster method classifies evaluation objects by sum of squares of deviations $[10,11]$. It is set that: $\mathrm{n}$ companies are divided into k types, wherein $S_{i}$ is the $i$ type of sum of squares of deviations $(i=1,2, \mathrm{k}), n_{i}$ is the number of companies of $i$ type, $X_{i}^{(j)}$ is the comprehensive evaluation score of the $j$ company of $i$ type $(j=1,2, \mathrm{n})$, and $\overline{X_{i}}$ is the score mean of $i$ type, so sum of squares of deviations $S_{i}$ of $i$ type is:

$S_{i}=\sum_{j=1}^{n_{i}}\left(X_{i}^{(j)}-\overline{X_{i}}\right)^{2}$

Sum of squares of deviations $\mathrm{S}$ of $\mathrm{k}$ types is:

$S=\sum_{i=1}^{k} \sum_{j=1}^{n_{i}}\left(X_{i}^{(j)}-\overline{X_{i}}\right)^{2}$

Steps of Ward cluster method:

$\ominus \mathrm{n}$ companies are deemed as $\mathrm{n}$ types.

$\ominus$ Any 2 ones in $\mathrm{n}$ companies are combined into a type. Others are not changed. In this way, $n(n-1) / 2$ combination schemes are obtained.

Sum of squares of deviations of each combination scheme is calculated according to formula (13). New classification is carried out as per the combination scheme with the smallest sum of squares of deviations.

$\circledast$ Step $\ominus$ is repeated till the final classification number is $\mathrm{k}$.

\section{APPLICATION EXAMPLE}

A supplier's selection of a decision activity is simplified: there are 3 alternative schemes $\left(A_{1}, A_{2}, A_{3}\right)$ and 5 codes 
Table 1. Each property utility value and property weight of alternative scheme.

\begin{tabular}{|c|c|c|c|c|}
\hline & $A_{1}$ & $A_{2}$ & $A_{3}$ & Weight \\
\hline \hline $\mathrm{C}_{1}$ & $(0.79,0.19,0.18)$ & $(0.82,0.19,0.15)$ & $(0.81,0.18,0.11)$ & 0.22 \\
\hline $\mathrm{C}_{2}$ & $(0.71,0.22,0.19)$ & $(1.1,0.2,0.1)$ & $(0.88,0.18,0.12)$ & 0.23 \\
\hline $\mathrm{C}_{3}$ & $(0.76,0.21,0.14)$ & $(0.98,0.13,0.02)$ & $(0.91,0.18,0.12)$ & 0.21 \\
\hline $\mathrm{C}_{4}$ & $(0.97,0.14,0.04)$ & $(1,0.2,0.12)$ & $(0.9,0.2,0.1)$ & 0.22 \\
\hline $\mathrm{C}_{5}$ & $(0.51,0.21,0.22)$ & $(0.91,0.2,0.1)$ & $(0.83,0.2,0.14)$ & 0.15 \\
\hline
\end{tabular}

Table 2. Distance between property utility value and ideal solution.

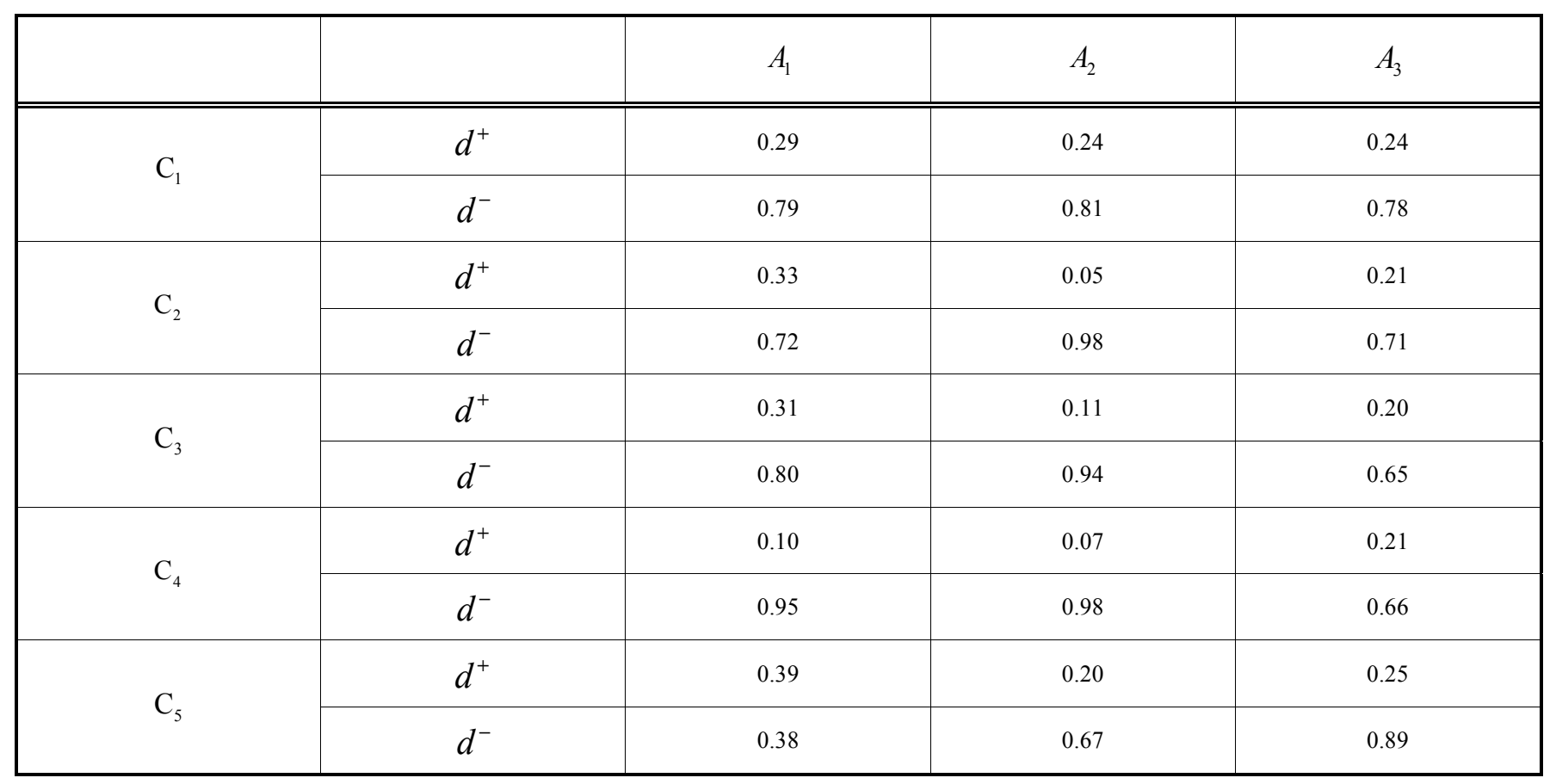

Table 3. Relative similarity degree between alternative scheme and ideal solution.

\begin{tabular}{|c|c|c|c|}
\hline Scheme & Distance to Positive Ideal Solution & Distance to Negative Ideal Solution & Relative Similarity Degree \\
\hline \hline$A_{1}$ & 0.28 & 0.79 & 0.72 \\
\hline$A_{2}$ & 0.11 & 0.89 & 0.88 \\
\hline$A_{3}$ & 0.22 & 0.71 & 0.74 \\
\hline
\end{tabular}

$\left(\mathrm{C}_{1}, \mathrm{C}_{2}, \mathrm{C}_{3}, \mathrm{C}_{4}, \mathrm{C}_{5}\right)$, while specific data is shown in Table 1.

According to data in Table $\mathbf{1}$, distances between 5 property utility values of each alternative scheme to positive and negative ideal solutions are worked out by the formula (9), as shown in Table 2.

Then relative similarity degrees between alternative schemes and ideal solutions are worked out by the formula (10) according to data in Table 2 , as shown in Table 3.
At last, variation coefficients of alternative scheme properties are worked out by the formula (13), while results are shown in Table 4.

Evaluation results obtained by the TOPSIS method based on utility theory are listed in Table 5. As a contrast, a fuzzy TOPSIS method is also given.

It is shown in data of Table 5 that decision-making results obtained by both the improved TOPSIS method put forward in the paper and the standard TOPSIS method with 
Table 4. Variation coefficient of alternative scheme property.

\begin{tabular}{|c|c|c|c|c|}
\hline \multicolumn{2}{|c|}{ Scheme } & $A_{1}$ & $A_{2}$ & $A_{3}$ \\
\hline \multirow{2}{*}{ Positive Ideal Solution } & Mean & 0.26 & 0.14 & 0.21 \\
\hline & Standard Deviation & 0.12 & 0.09 & 0.04 \\
\hline \multirow{2}{*}{ Negative Ideal Solution } & Mean & 0.72 & 0.89 & 0.74 \\
\hline & Standard Deviation & 0.22 & 0.14 & 0.09 \\
\hline \multicolumn{2}{|c|}{ Variation Coefficient } & 0.33 & 0.25 & 0.14 \\
\hline
\end{tabular}

Table 5. Final calculation results.

\begin{tabular}{|c|c|c|}
\hline Scheme & Fuzzy TOPSIS Method & This Paper \\
\hline \hline$A_{1}$ & 0.74 & 0.54 \\
\hline$A_{2}$ & 0.90 & 0.76 \\
\hline$A_{3}$ & 0.79 & 0.71 \\
\hline
\end{tabular}

application of fuzzy data are completely the same, namely that scheme A2 is better than scheme A3 and scheme A1.

\section{CONCLUSION}

The paper introduces subjective utility judgment into the standard TOPSIS decision-making method, also takes decision makers' comprehensive evaluation of each property utility value into account and sets a property variation coefficient of each alternative scheme. In view of uncertainty in decision making by decision makers, a triangular fuzzy number is used to describe the utility value of each piece of property data. By determining evaluation scores with TOPSIS, limitation to sample quantity and data distribution is avoided and the method is more suitable to a capital market environment with insufficient observable sample data; Ward cluster analysis is carried out to sample companies according to comprehensive scores obtained by TOPSIS based on utility theory in order to reveal significant differences of comprehensive financial performances of different companies.

\section{CONFLICT OF INTEREST}

The author confirms that this article content has no conflict of interest.

\section{ACKNOWLEDGEMENTS}

Declared none.

\section{REFERENCES}

[1] A. Wall, "Prevention of a first stroke: a review of guidelines and a multidisciplinary consensus statement from the National Stroke Association," JAMA, vol. 281, no. 12, pp. 1112-1120, 1929.

[2] M. Bovee, A. Kogan, K. Nelson, R.P. Srivastav, and M.A. Vasarhelyi "Financial reporting and auditing agent with net knowledge (FRAANK) and extensible business reporting language (XBRL)," Journal of Information Systems, vol. 19, no. 1, pp. 19-41, 2005.

[3] G. Ambrose, Z. S. Eugene, and F. Li, "Experimental evaluation of multiple criteria decision models for application to water resources planning," Journal of the American Water Resources Association, vol. 28 , no. 1 , pp. 89-102, 1992.

[4] P. Salminen, J. Hokkanen, R. Lahdelma, "Comparing multicriteria methods in the context of environmental problems," European Journal of Operational Research, vol. 104, no. 3, pp. 485-496, 1998.

[5] M.L. Bell, B.F. Hobbs, and H. Ellis, "The use of multi-criteria decision-making methods in the integrated assessment of climate change: implications for IA practitioners," Socio-Economic Planning Sciences, vol. 37, no. 04, pp. 289-316, 2003.

[6] C.B. Chen, and C.M. Klein, "A simple approach to ranking a group of aggregated fuzzy utilities," Systems, Man, and Cybernetics, Part B: Cybernetics, IEEE Transactions on, vol. 27, no. 1, pp. 26-35, 1997.

[7] F.T.S. Chan, and N. Kumar, "Global supplier development considering risk factors using fuzzy extended AHP-based approach," Omega, vol. 35, no. 4, pp. 417-431, 2007.

[8] G.Y.Chen, C.J. Goh, and X.Q. Yang, "Vector network equilibrium problems and nonlinear scalarization methods," Mathematical Methods of Operations Research, vol. 49, no. 2, pp. 239-253, 1999.

[9] F. Tao, Y. Cheng, L. Zhang, and D. Zhao, "Utility modelling, equilibrium, and coordination of resource service transaction in serviceoriented manufacturing system," In: Proceedings of the Institution of Mechanical Engineers, Part B: Journal of Engineering Manufacture, vol. 226, no. 6, pp. 1099-1117, 2012.

[10] L.T. Warren, "Clustering of time series data: a survey," Pattern Recognition, vol. 38, no. 11, pp. 1857-1874, 2005.

[11] C. Köbrich, T. Rehman, and M. Khan, "Typification of farming systems for constructing representative farm models: two illustrations of the application of multi-variate analyses in Chile and Pakistan," Agricultural Systems, vol. 76, no. 1, pp. 141-157, 2003.

Received: June 10, 2015

Revised: July 29, 2015

Accepted: August 15, 2015

(C) Ge Hong; Licensee Bentham Open.

This is an open access article licensed under the terms of the (https://creativecommons.org/licenses/by/4.0/legalcode), which permits unrestricted, noncommercial use, distribution and reproduction in any medium, provided the work is properly cited. 